\title{
Some Effects of Motor-car Driving on the Normal and Abnormal Heart
}

\author{
PETER TAGGART,* M.B., M.R.C.P., M.R.C.P.ED. ; DAVID GIBBONS, $\dagger$ M.S.C.T. \\ WALTER SOMERVILLE, $\ddagger$ M.D., F.R.C.P.
}

$S^{\min }$ mmary : Electrocardiograms were recorded in experienced motor-car drivers accustomed to busy city traffic while driving their own cars along familiar routes. The majority with normal hearts or a history of coronary heart disease increased their heart rates; brief periods when the rate exceeded $140 / \mathrm{min}$. were recorded in both groups. ST changes not caused by tachycardia developed in 3 out of 32 normal drivers. Of 24 drivers with coronary heart disease 13 increased their ST and T abnormalities, the changes being gross in six. A further five developed multiple ventricular ectopic beats. Two coronary drivers experienced anginal pain and two left ventricular failure. Healthy motor-racing drivers increased their heart rates to $180 / \mathrm{min}$. in the few minutes before the start of a race and to above $200 / \mathrm{min}$. while racing.

Little or no change in the plasma catecholamine levels was noted in three coronary subjects immediately after a city drive compared with resting levels. All the racing drivers showed a considerable increase in noradrenaline, and in one instance adrenaline, immediately after racing.

Persons in whom angina is easily provoked when driving or who are in borderline left ventricular failure should be advised not to drive.

\section{Introduction}

Rapid heart rates and abnormal ST and $T$ changes in the electrocardiogram (E.G.G.) have been recorded in persons with apparently normal hearts during driving in busy London traffic (Taggart and Gibbons, 1967). The object of the present study was to extend the observations to a larger number of persons with clinically normal hearts and to persons with different forms of heart disease. Driving being a fairly common provocative factor of angina pectoris, the purpose of including persons with coronary heart disease in the study was to find out whether the driver's heart rate was related to the production of angina, and to note the behaviour of the ischaemic E.C.G. under the everyday stress of driving. We have here considered only certain common heart conditions. We have included observations made during motor racing in an attempt to record some of the responses of the normal heart to excitement and intense competition divorced from the effects of physical activity. Plasma catecholamine levels were measured in relation to ordinary town driving and competitive racing.

The data were obtained from a group of 78 people consisting of 32 with apparently normal hearts, 29 with abnormal hearts, the majority with coronary heart disease, and 17 racing drivers, the preliminary details of which have been reported (Somerville, Taggart, and Gibbons, 1968).

\section{Methods and Equipment}

The development of the radioelectrocardiograph (Holter and Generelli, 1949) has provided a convenient and practical method of recording the E.C.G. free from cumbersome limb leads.

* Research Assistant.

+ Senior Cardiological Technician.

† Physician.

Department of Cardiology, Middlesex Hospital, London W.1.
The model used, the C. \& M. Radioelectrocardiograph, consists of a transmitter carried by the patient and a receiver and tape recorder controlled by the operator.

Transmitter. ${ }^{1}$ - The radio transmitter is a compact 9-volt internal-battery-operated unit, measuring $6 \frac{1}{4} \times 3 \frac{3}{4} \times 1 \frac{3}{4}$ in. $(16 \times 9.5 \times 4.5 \mathrm{~cm}$. $)$ and weighing $1 \frac{1}{4} \mathrm{lb}$. $(570 \mathrm{~g}$. $)$ and is conveniently carried in the subject's pocket. The patient leads consist of two fine wires which pass under the subject's clothing connecting the transmitter to the chest electrodes. The Devices press stud electrodes were found to be the most suitable and were attached to the chest wall with the fixed electrode at the sternal angle and the exploring electrode in the V5 or V6 position, to give a left ventricular QRS configuration.

Receiver.-The receiver is a compact unit measuring $10 \frac{1}{4}$ by $6 \frac{1}{2}$ by 4 in. (26 by $16 \cdot 5$ by $10 \mathrm{~cm}$.) weighing $5 \mathrm{lb} .(2 \cdot 3 \mathrm{~kg}$.) and is operated by an internal 9 -volt battery.

Tape Recorder.-The tape recorder used was the UHER 4,000 Report/L with a microphone attachment which provided an accurate method of marking the recording with a note of events happening during the drive. The receiver relayed the recording to the tape recorder through a short connecting cable, and both were operated without difficulty from the back seat of the car.

Playback.-The transmitted E.C.G. was subsequently played back from the tape recorder through the receiver to a conventional electrocardiograph and oscilloscope, so that after studying the complete recording any relevant sections could be written out on to conventional paper and kept as a permanent record.

Selection of Subjects.-A group of normal subjects was selected to include as wide a range of age and driving experience as possible. No one had a history of heart disease and the 12-lead E.C.G. was normal. A second group of persons with abnormal hearts consisted mainly of patients with coronary heart disease. At the time of the tests all were following their usual occupations. They were experienced drivers and used their cars daily in London traffic. Each subject had a complete physical examination and a 12-lead E.C.G. was recorded before and after the drive.

Driving Procedure.-The monitoring lead was recorded in the standing, sitting, and lying positions before the test to detect any postural effect on the QRS configuration. The subjects drove their own cars accompanied by one of us for about 20 minutes in the vicinity of Picadilly Circus and Trafalgar Square in London, a route well known to them, beginning and ending the drive at the Middlesex Hospital. We tried to lead each driver into traffic of comparable density, and so details of the route varied slightly from person to person. The subjects were asked to drive in their customary manner and were assured we were not concerned with their driving proficiency. They were neither questioned nor harassed about their use of the road and contrived hazards and tricky manœuvres were avoided. Smoking was not forbidden, but in fact none of the drivers smoked during the test. We tried to avoid introducing artificiality and anxiety which could colour the findings.

\footnotetext{
1 The operating frequency of the transmitter was $169 \cdot 75$ megacycles with audio frequency amplitude modulation. The frequency response was $1-500 \mathrm{~Hz}+2 \mathrm{db}$. The receiver was matched to the frequency of the transmitter and produced a low impedance output to the tape recorder. When used in the playback procedure a high impedance output after demodutation was fed into the electrocardiogram. The tape recorder frequency response was $40-20,000 \mathrm{~Hz}$.
} 
Racing Drivers. - In the case of the racing drivers, whenever space permitted the tape recorder and receiver were secured inside the car before the start of the race. This system of recording was limited to saloon and sports car races, as there was insufficient space for the equipment in single-seater racing cars. The tape recorder was tested to eliminate any variation in recording speed that might occur under the high $g$ forces encountered during braking and comering and found to be satisfactory. For the single-seater events the tape recorder and receiver were positioned in the centre of the circuit. The transmitting frequency allocated by the General Post Office, however, limits the range to a few hundred yards, so that in these events the recording was intermittent and suffered in quality.

Plasma Catecholamine Levels.-Differential estimation of plasma noradrenaline and adrenaline was performed on four town drivers and seven racing drivers by the method of Anton and Sayre (1962). Thirty millilitres of heparinized blood was mixed with sodium metabisulphite, immediately centrifuged, and the plasma deep-frozen until analysed. The analysis involves the selective adsorption of the catecholamines on to aluminium oxide, elution with perchloric acid, and their measurement by the formation of a fluorescent trihydroxyindole derivative in the presence of potassium ferricyanide and alkaline ascorbate.

\section{Results}

Seventy-eight subjects have been studied, including 32 with apparently normal hearts, 24 with coronary heart disease, 4 with rheumatic heart disease, 1 with myocardiopathy, and 17 racing drivers. The results in those with normal hearts and coronary heart disease are summarized in Table $\mathrm{I}$.

TABLE I.-Results in Subjects with Normal and Abnormal Hearts

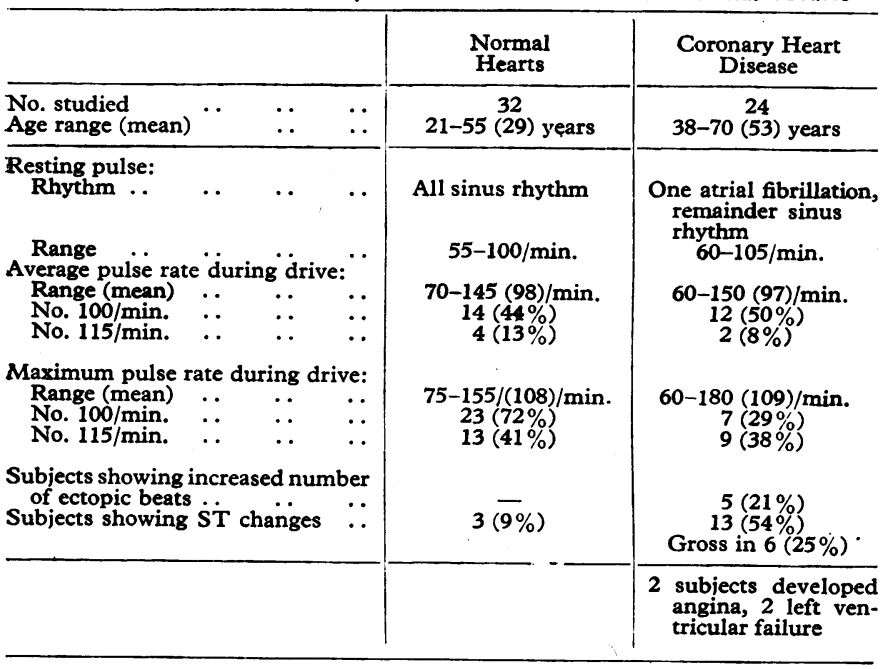

\section{Subjects with Normal Hearts}

In the group without heart disease a wide variation in heart rate occurred. No increase compared with the resting rate was noted in $3(9 \%)$, while the remainder all developed some degree of tachycardia, the fastest rates reaching $155 / \mathrm{min}$. There was no correlation between the degree of tachycardia and the age, sex, experience, or temperament of the driver.

$S T$ depression and flattening of $T$ waves of a greater degree than that expected with ta:hycardia alone were recorded in three subjects.

\section{Subjects with Abnormal Hearts}

In the 24 subjects with coronary heart disease again a wide variation in heart rate occurred. No increase compared with the resting rate occurred in $3(12 \%)$. All the others developed some degree of tachycardia, the fastest rate recorded being $180 / \mathrm{min}$. Ischaemic ST changes occurred in $13(54 \%)$ and were gross in $6(25 \%)$.

Ectopic Beats.-Five subjects with coronary heart disease in sinus rhythm developed multiple ectopic beats while driving.

A woman aged 50 had effort angina for one year. She drove her car to work in London every day and had not experienced palpitation or angina while doing so. During the test her E.C.G. showed frequent multifocal ventricular ectopic beats with occasional short runs of ventricular tachycardia (Fig, 1). She had no complaints at the time, and particularly was not troubled by palpitation or chest pain.

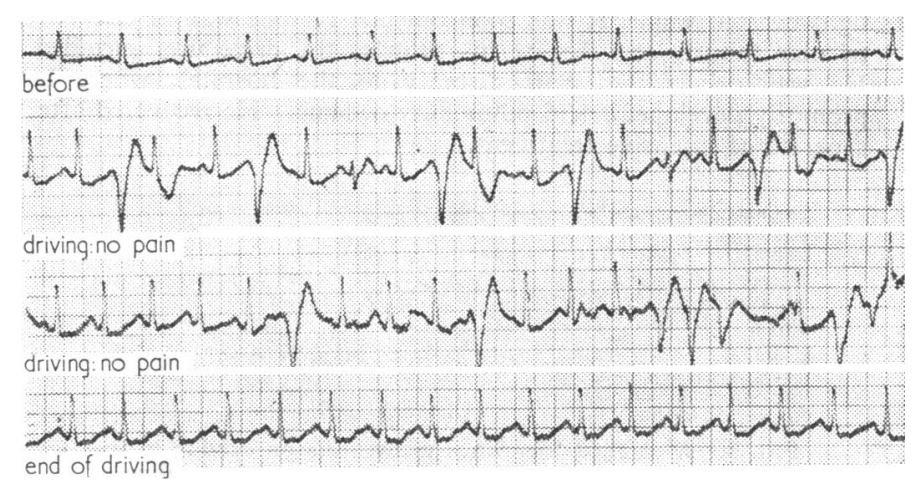

FIG. 1.-Woman aged 50. Multifocal ventricular ectopics appear during driving in subject with history of angina. A brief run of ventricula tachycardia is shown on third strip. The subject had no symptoms during the drive.

Multiple ventricular ectopic beats occurring during driving were also found in a man aged 39 who had made an uneventful recovery from a myocardial infarction two years previously and drove to work daily. In these two patients, as well as in the three others with coronary heart disease, the ectopic activity subsided when the drive ended.

Angina Pectoris.-Two of the subjects with coronary heart disease developed angina pectoris during the test drive, ST changes appearing in both.

A man aged 53 developed angina following a myocardial infarction in 1962. He usually required 2-6 trinitrin tablets a day and on occasion experienced angina while driving. He drove his own car every day into London, where he worked a full day as an underwriter. On starting his test drive he was symptomfree and the E.C.G. was unchanged from the control tracing. After three minutes' driving prominent ST depression appeared with frequent ventricular ectopic beats (Fig. 2). Five minutes later he developed anginal pain requiring him to stop and take a trinitrin tablet. After a short pause he was able to drive back to the starting-point without further pain.

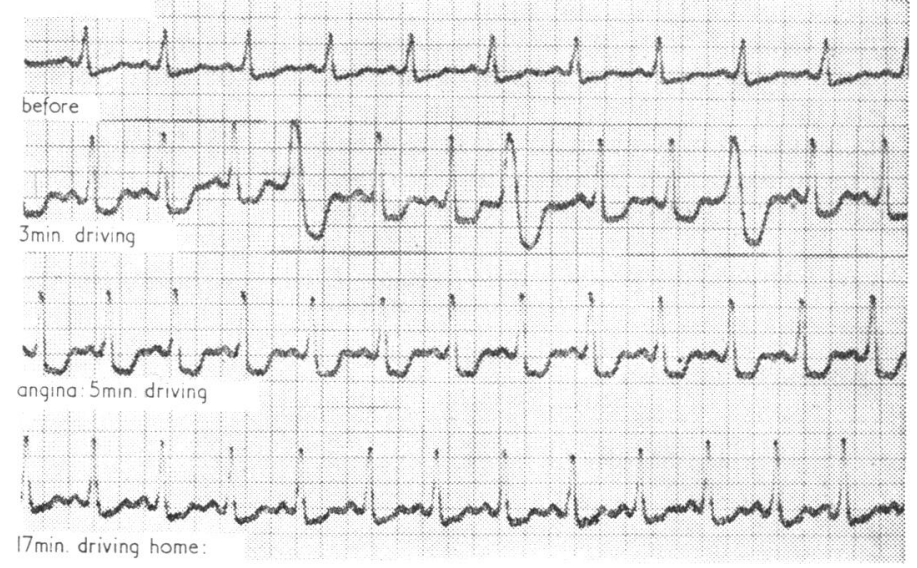

FIG. 2.-Man aged 53, myocardiad infarction six years previously. Feart rate increased and ventricular ectopics appeared with driving, preceding onset of angina (third strip). 
Pulmonary Oedema.-One subject developed florid pulmonary oedema during the drive, and a second had early left ventricular failure.

A man aged 55, referred to us by Dr. A. Hollman, developed a left ventricular aneurysm following a myocardial infarction in 1962. A second infarction in 1965 precipitated left ventricular failure, and since then he has been maintained on anti-failure measures. He had occasional angina, but he drove his car every day into London, where he worked a full day. Almost immediately on starting the test drive his heart rate increased from 90 to $150 / \mathrm{min}$. (Fig. 3). A rate of 150 was maintained continuously until the latter part of the drive, when it increased to $180 / \mathrm{min}$. At this time he developed a dry persistent cough, which he said often troubled him if the traffic was heavy. Throughout the drive he had been in high spirits, talking in a light-hearted way. It was soon obvious that he was in left ventricular failure, and despite his protests the drive was curtailed. $\mathrm{He}$ was driven the short distance to the hospital, where he promptly developed florid pulmonary oedema. He recovered after a period of intensive treatment.

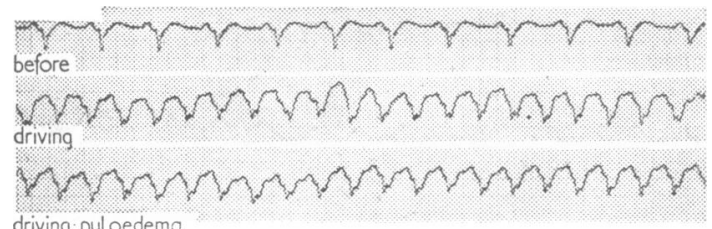

Fig. 3.-Man aged 55. Sinus tachycardia on driving in a man with ventricular aneurysm of six years' standing Pulmonary oedema developing towards the end of the drive.

The second subject, a man aged 62 with coronary heart disease, in full-time employment, developed dyspnoea and the test was curtailed. Although his heart rate had increased only from 75 at rest to 110 during the drive, $2 \mathrm{~mm}$. of ST depression had developed on the E.C.G.

Atrial Fibrillation.-Two subjects with atrial fibrillation, one with coronary heart disease and the other with a myocardiopathy of unknown aetiology, increased their heart rates from 100 to $170 / \mathrm{min}$. and from 65 to 140 respectively (Fig. 4). Both were taking digitalis and were unaware of symptoms during the drive.

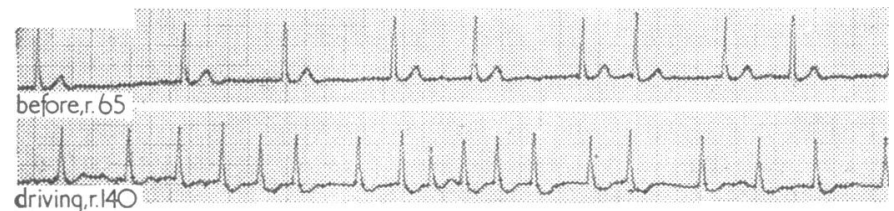

FIG. 4.-Man aged 47. Atrial fibrillation in a man with a myocardiopathy. During an uneventful drive the ventricular rate increased to $140 / \mathrm{min}$.

Rhermatic Heart Disease.-Four persons were studied, all daily motorists: a man aged 63 with mitral valve disease, a man aged 58 with aortic valve disease, and a woman aged 46 and a woman aged 60 , both with mitral and aortic valve disease. All these subjects were in sinus rhythm. Their heart rates increased from a mean of 71 at rest to 90 while driving, with a mean maximum of $100 / \mathrm{min}$. No fresh E.C.G. changes were observed and all remained symptom-free.

TaBle II.-Plasma (Venous) Catecholamine Levels ( $\mu$ g./litre) After City

\begin{tabular}{c|c|c|c|c|c}
\multicolumn{8}{c}{ Driving and at Rest } \\
\hline \multirow{3}{*}{$\begin{array}{c}\text { Driver } \\
\text { No. }\end{array}$} & \multirow{2}{*}{ Diagnosis } & \multicolumn{2}{|c}{ Immediately after Drive } & \multicolumn{2}{c}{ Later } \\
\cline { 3 - 6 } & & Noradren. & Adren. & Noradren. & Adren. \\
\hline 1 & Cardiac infarction & 0.38 & 0.48 & 0.36 & 0.53 \\
2 & Cardiac infarction & 0.84 & 0.35 & 0.32 & 0.40 \\
3 & Angina pectoris & 0.34 & 0.38 & 0.23 & 0.45 \\
4 & Normal & 0.20 & 0.27 & 0.23 & 0.07 \\
\hline
\end{tabular}

Plasma Catecholamine Levels.-Plasma catecholamine levels were measured in three men with coronary heart disease and one normal woman after a drive through busy city traffic (Table II). For comparison, repeat estimations were made some days later. The changes were generally insignificant and inconsistent.

\section{Racing Drivers}

Ten healthy experienced racing drivers were tested during competitive motor racing. During the 15-minute period before the start heart rates of 150 to 180 were recorded in all 10 drivers, increasing to between 180 and 210 by the time of the start. The rate was maintained at this level throughout the 20 minutes of the event (Fig. 5). None of the racing drivers was aware of palpitation or any symptom other than the natural apprehension experienced before and during any competitive event.
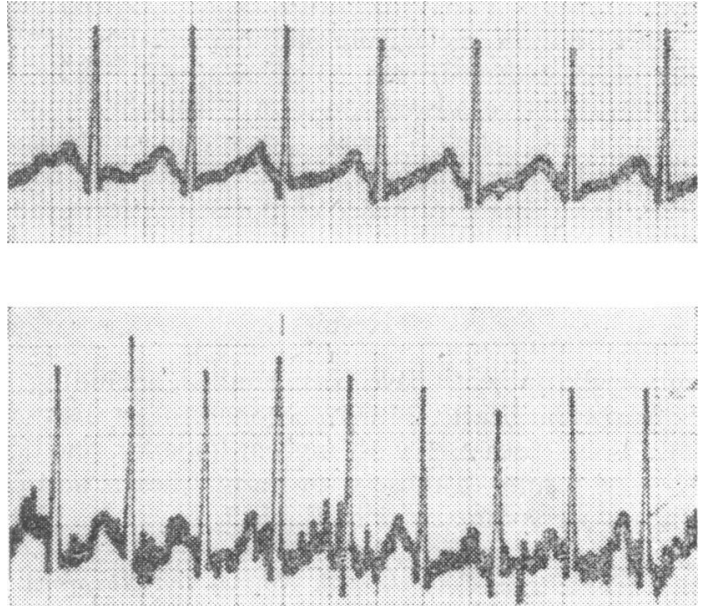

FIG. 5.-Racing driver. Top: 5 minutes before start of

motor race. Bottom : One minute after start, approach
ing a sharp bend at about $115 \mathrm{~m} . \mathrm{p.h}$. (185 km.p.h.).

Plasma Catecholamine Levels.-Blood adrenaline and noradrenaline estimations were performed on a further seven drivers (Table III). The blood was taken within 10 minutes of completion of the race and a further specimen one hour to two days later for comparison. All the latter values were within normal limits. The levels at the end of the race were raised in all cases, in some being as high as 20 times the resting sample.

TABLE III.-Plasma (Venous) Catecholamine Levels ( $\mu \mathrm{g} . /$ litre) in Racing Drivers

\begin{tabular}{r|c|c|c|c|c|c}
\hline $\begin{array}{r}\text { Driver } \\
\text { No. }\end{array}$ & \multicolumn{2}{|c|}{ Immediately after Race } & \multicolumn{3}{c}{ Later } \\
\cline { 2 - 4 } \cline { 5 - 6 } & Noradren. & Adren. & Heart Rate & Noradren. & Adren. & Heart Rate \\
\hline 5 & 6.81 & 2.13 & 124 & 0.17 & 0.49 & 112 \\
6 & 1.36 & 0.72 & 193 & 0.42 & 0.57 & 120 \\
7 & 5.06 & 0.12 & 115 & 0.30 & 0.39 & 90 \\
8 & 1.26 & 0.26 & 140 & 0.41 & 0.30 & \\
9 & 2.28 & 0.17 & 140 & & & \\
10 & 1.06 & 0.29 & 160 & & & \\
11 & 1.05 & 0.30 & 130 & & &
\end{tabular}

\section{Discussion}

Motor-car driving in busy city traffic under the conditions of these tests caused tachycardia and ST changes in the E.C.G. in certain persons with normal hearts. Furthermore, ectopic beats, arrhythmias, ischaemic ST depression, angina pectoris, and pulmonary oedema develored in drivers with abnormal hearts, especially coronary heort disease (a history of angina pectoris or of previous myocardial infarction). It is tempting to suggest that all these reactions stem from a common provocative factor-namely, a catecholamine release-and that the same factor is responsible for the extreme degree of sinus tachycardia in racing drivers with normal hearts. 
Some degree of rate increase was recorded in 29 of the present group of 32 normal town drivers, the rate exceeding 100 in $23(72 \%)$. The following factors to a greater or less extent influenced the town drivers with normal or abnormal hearts: increased awareness of danger, competition to manœuvre into the fastest-moving traffic lane, aggravation by other drivers, and impatience from delays in dense traffic. The sensitivity of the different drivers to these influences varied, but we were unable to correlate the intensity of the rate response with age, sex, driving experience, or temperament by means of the roughand-ready criteria of the driver's attitude and method of driving his car.

These findings are in broad agreement with the observations of Hoffmann (1965), who noted an increase in heart rate with city driving, aggravated by any driving crisis. Driving tests on 65 normal young men lasting two and a half hours but avoiding areas of extremely heavy traffic produced tachycardia of up to $145 / \mathrm{min}$. in some but no change in others (Bellet, Roman, Kostis, and Slater, 1968). ST depression and flat $T$ waves were recorded by Hoffmann (1965) in healthy persons during city driving, similar to the findings in three of our healthy drivers. These changes are the resultant of tachycardia and emotion. Each of these two factors was appraised separately in a woman aged 21 . In the course of her test she narrowly avoided an accident and, without hyperventilating, immediately developed sinus tachycardia of $120 / \mathrm{min}$. with simultaneous ST depression. Four days later, under resting tranquil conditions, the heart rate was increased to $120 / \mathrm{min}$. by intravenous atropine, $1.2 \mathrm{mg}$. The ST segments and T waves remained unaffected. At this point a frightening situation was contrived by a stranger bursting into the room shouting and waving his arms, whereupon the ST segments promptly dipped and T-wave flattening occurred (Fig. 6). Similar ST and $T$ changes were induced in this subject by exercise and hyperventilation.

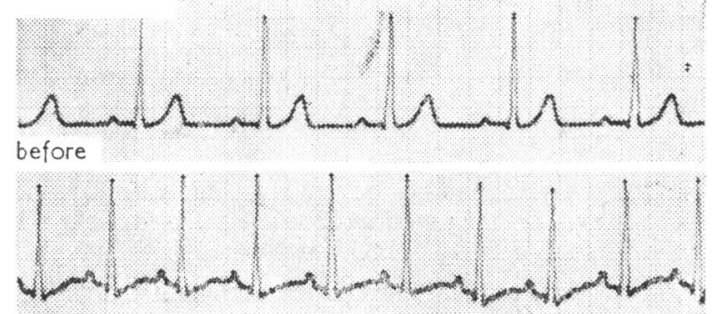

anxiety situation while driving

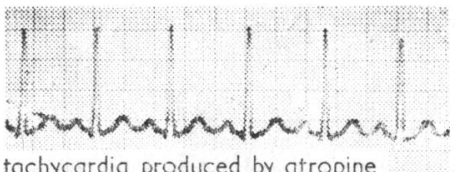

tachycardia produced by atropine

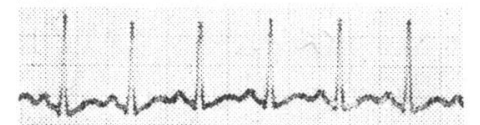

fright after atropine-induced tachycordia

FIG. 6.-Woman aged 21. Sinus tachycardia on narrowly avoiding an accident (second strip). The bottom two strips show the effect of a sudden fright on the electrocardiogram when the rate had been increased by atropine.

The ST and $\mathrm{T}$ deviations in the other two normal drivers, both middle-aged men, were not related to any acute anxiety situation during the drive. These electrocardiographic changes bear some resemblance to those of myocardial ischaemia, and if the occasion were an exercise test the result would be classed as "suspect" or "positive." It may well be that the two middle-aged men were in fact developing pain-free ischaemic patterns provoked by emotion rather than exercise, but this was most unlikely in the 21-year-old woman.
The situation is comparable to the well-known fact that electrocardiographic patterns recorded during prolonged intense emotion in certain highly strung but otherwise normal persons may closely mimic those of myocardial ischaemia. These tracings may be made strictly normal by deep sedation, and when the latter wears off the original ST depression returns (Fig. 7).
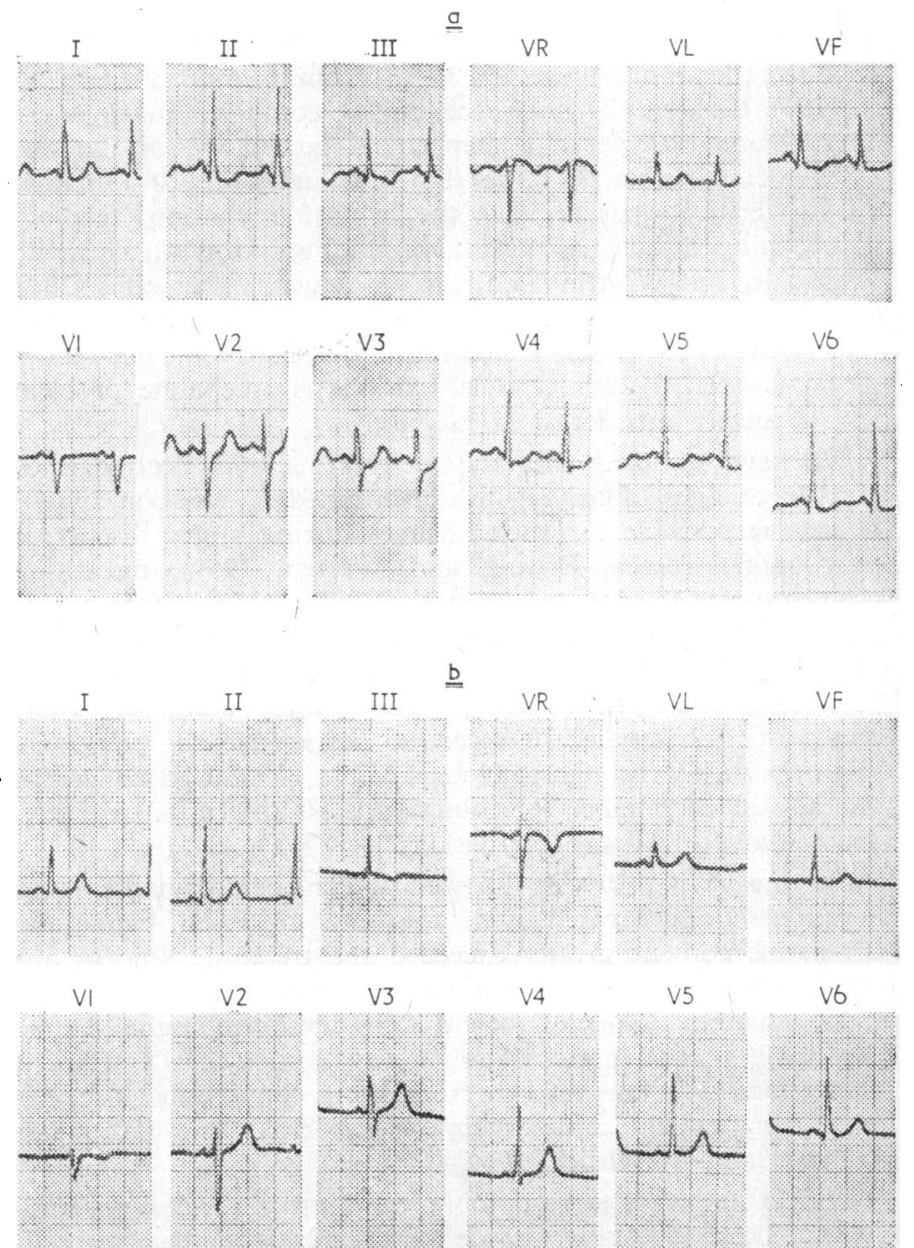

Fig. 7.-Effect of deep sedation on the electrocardiogram of an anxious young woman with a normal heart. (A) Highly anxious state. (B) Heavy sedation.

The incidence of myocardial ischaemic manifestations was higher than expected; of the 24 coronary subjects, $13(54 \%)$ showed a total of 22 different ischaemic patterns during the test drive ( 2 angina, 2 left ventricular failure, $13 \mathrm{ST}$ and T abnormalities, and 5 multiple ventricular ectopics). This is a considerably higher incidence of driving-induced myocardial ischaemia than the $17 \%$ reported by Bellet et al. (1968). The explanation may lie in different traffic conditions or the fact that our subjects were accompanied by one of us during the test drive. This arrangement was designed to be reassuring, but may have had the opposite effect.

While there is some evidence that syncope during driving from coronary heart disease is an uncommon cause of fatal traffic accidents (Peterson and Petty, 1962; Myerburg and Davis, 1964), there is nevertheless a requirement that persons with certain coronary syndromes be advised against driving even in a private capacity. The most obvious one is AdamsStokes attacks with an ischaemic basis. The present tests, even allowing for a certain amount of unavoidable artificiality, suggest strongly that anginal attacks provoked by town traffic, and borderline failure resulting from severe left ventricular disease such as a left ventricular aneurysm, should be contraindications to holding a driving licence. These matters were summarized by the Medical Commission on Accident Prevention (1968). 
The racing drivers were influenced by two main determinants-competition and danger-both acting in concert during the race but only in an anticipatory sense before the start, yet capable of consistently inducing heart rates exceeding $130 / \mathrm{min}$. Extremely rapid sinus tachycardia of the same order (180-200/ min.) was reported in racing drivers by Collins (quoted by Simonson, Baker, Burns, Keiper, Schmitt, and Stackhouse, 1968 ) and a somewhat slower heart rate $(120-160 / \mathrm{min}$.) by Rapp, Dietlein, and Nuttall (1965) over a two-hour race. We have recorded a heart rate of $120-130 / \mathrm{min}$. in the third hour of the 1968 Le Mans 24-hour race, but we could not continue the observations because of a mechanical breakdown of the car. Certain civil airline pilots develop heart rates of $120-130 / \mathrm{min}$. during critical periods of the flight, including take-off, approaching a busy airport, and landing (Howitt, Backwill, Whiteside, and Whittingham, 1965). Much higher rates (200$240 / \mathrm{min}$.) have been documented in oarsmen after a 500 -metre race (J. L. Corbett, personal communication, 1968), but tachycardia associated with physical exercise is a separate problem and is merely mentioned in passing.

We have assumed that the tachycardia and electrocardiographic changes of driving are determined by emotion similar to that responsible for such changes during angry discussion (Bogdonoff, Combs, Bryant, and Warren, 1959), discussing problems of personal importance (Wolff, 1950), before examinations (Bogdonoff, Estes, Harlan, Trout, and Kirschner, 1960), and after a sudden fright induced by a pistol shot (Graybriel and White, 1935). The ectopic beats and short bursts of tachycardia we recorded have a similar emotional origin, probably through the intermedium of induced ischaemia. Excess catecholamine secretion appears to be a common denominator in all these situations.

All the racing drivers showed a considerable increase in noradrenaline compared with the tranquil levels, while the adrenaline content greatly exceeded the tranquil value in one driver only. The city drivers showed insignificant and inconsistent changes. None of these drivers developed angina during the drive, though both drivers 1 and 2 showed ST segment depression. Previous workers have shown considerable increases in urinary catecholamine excretion in drivers and passengers (Schmid and Meythaler, 1964).

We do not wish to read too deeply into these few observations. There is clearly a wide variance between the catecholamine response in different racing drivers. Many factors will have to be investigated before the meaning of these findings is understood, including the driver's personality, the intensity of the competitive element in the race, the mechanical behaviour of the car, and the driver's body temperature involving considerable fluid loss into the anti-inflammable underwear. The city drivers, showing much smaller changes in catecholamine levels between the after-drive and "control" samples, were not exposed to anything like the same driving variables as the racing drivers. We present the findings now as preliminary observation which will form the basis for future tests.

We wish to thank the Automobile Association and the Medical Commission on Accident Prevention, who provided financial support ; the Ford Motor Company for lending us a Ford Transit Minibus for transporting equipment to the racing circuits; the officials of the 24-Hour Le Mans Race and Dr. Peter Riley and Mr. J, G. W. Marsh, of Marcos Cars Ltd., for assisting us at Le Mans; the officials of the Royal Automobile Club, British Automobile Racing Club, and British Racing and Sports Car Club for helping us at the race meetings; Medical and Industrial Equipment Ltd., and Ernest Turner Electro Instruments Ltd., for assistance with equipment; and many others, including the drivers themselves.

We are grateful to Dr. Lawson McDonald, the London Hospital, for help with the plasma catecholamine estimations and Miss Carol Baker, who performed the tests.

\section{REFERENCES}

Anton, A. H., and Sayre, D. F. (1962). Fournal of Pharmacology and Experimental Therapeutics, 138, 360.

Bellet, S. Roman, L., Kostis, J., and Slater, A. (1968). American fournal of Cardiology, 22, 856

Bogdonoff, M. D., Combs, J. J, Bryant, G. D. N., and Warren, J. V. (1959). Circulation, 20, 353.

Bogdonoff, M. D., Estes, E. H., Harlan, W. R., Trout, D. L., and Kirschner, N. (1960). Fournal of Clinical Endocrinology and Metabolism, 20, 1333 .

Graybiel, A., and White, P. D. (1935). American Heart fournal, 10, 345 Hoffmann, H. (1965). Internist, 6, 292.

Holter, N. J., and Generelli, J. A. (1949). Rocky Mountain Medical fournal, 46, 747.

Howitt, J. S., Backwill, J. S., Whiteside, T. C. D., and Whittingham, P. D. G. V. (1965). Flying Personnel Research Committee, 1240.

Medical Commission on Accident Prevention (1968). Medical Aspects of Fitness to Drive Vehicles, edited by L. G. Norman. London, MediFal Commission onicles, edited by $\mathrm{L}$. $\mathrm{G}$.

Myerburg, R. J., and Davis, J. H. (1964). American Heart fournal, 68

586.
Peterson, B. J., and Petty, C. S. (1962). Fournal of Forensic Sciences, 7, 274.

Rapp, R. M., Dietlein, L. F., and Nuttall, J. C. (1965). Aerospace Medicine, 36, 159 .

Schmid, E., and Meythaler, C. (1964). Klinische Wochenschrift, 42, 139 Simonson, E., Baker, C., Burns, N., Keiper, C., Schmitt, O. H., an Stackhouse, S. (1968). American Heart fournal, 75, 125.

Somerville, W., Taggart, P. I., and Gibbons, D. (1968). Annals of Internal Medicine, 68, 1162.

Taggart, P., and Gibbons, D. (1967). British Medical fournal, 1, 411. Wolf, H. G. (1950). Circulation, 1, 187.

\title{
Recognition and Management of Dissecting Aneurysms of the Aorta
}

\author{
A. E. THOMPSON,* M.S., F.R.C.S. ; F. H. N. SPRACKLEN, $\dagger$ M.D., M.R.C.P. \\ E. M. M. BESTERMAN, $\ddagger$ M.D., F.R.C.P. ; L. L. BROMLEY,§ M.CHIR., F.R.C.S.
}

British Medical fournal, 1969, 4, 134-137

\begin{abstract}
Summary : The current approach to treatment at St. Mary's Hospital of dissecting aortic aneurysms uses a period of induced hypotension before aortography and consideration for surgical correction. There are 13 survivors of a series of 24 patients treated in this way.
\end{abstract}

\section{Introduction}

Aortic dissection is a lethal condition. The diagnosis, though not always easy, can usually be made on the clinical history and examination, and confirmed by radiology. As the early clinical features of acute dissection may mimic those of cardiac infarc- tion the distinction must be made, especially if anticoagulant therapy is contemplated.

At the present time there is no general agreement regarding the ideal management of dissecting aneurysms (Lindsay, 1969 ; Wheat and Palmer, 1968). The purpose of this paper is to present our recent experience at St. Mary's Hospital.

* Consultant Surgeon, St. Thomas's Hospital, London S.E.1. Late Assistant Director, Surgical Unit, St. Mary's Hospital, London W.2. † Late Senior Registrar, Department of Cardiology, St. Mary's Hospital London W.2. Present address: Groote Schuur Hospital, Cape Town, South Africa.

¥ Consultant Cardiologist, St. Mary's Hospital, London W.2.

Consultant Thoracic Surgeon, St. Mary's Hospital, London W.2 